\title{
El sistema financiero de Nueva Zelanda (1980-2004)
}

Geneviève Marchini*

$\mathrm{H}$ asta 1984 Nueva Zelanda era considerada como uno de los países desarrollados con mayor intervención pública en la economía. Desde la crisis mundial de los años treinta, el Estado había venido ampliando su intervención, inicialmente para proteger esta economía pequeña, abierta al comercio internacional, de fluctuaciones adversas provenientes de los mercados internacionales de los productos primarios agrícolas que constituyen hasta ahora la mayoría de sus exportaciones de bienes. A inicios de los ochenta la economía neozelandesa seguía protegida por elevadas barreras arancelarias, amplios subsidios y controles de capitales; se hallaba sujeta a una extensa reglamentación pública (precios y salarios, sectores productivos) y las empresas de propiedad estatal desempeñaban un papel muy relevante, en especial en los sectores primario y de servicios.

Desde la década de los setenta, marcada por la crisis del sistema internacional de cambios y los choques petroleros, y para Nueva Zelanda por la pérdida del acceso privilegiado a su principal mercado, el de Gran Bretaña, los resultados económicos y sociales habían sido cada vez más decepcionantes: el país presentaba un cuadro de estanflación más agudo que los demás integrantes de la OCDE, con un déficit público y una deuda externa elevados y necesidades

* Profesora-investigadora del Departamento de Estudios del Pacífico, e investigadora nacional (SNI). periódicas de devaluar el dólar neozelandés para restablecer la competitividad externa de sus exportaciones. El cuadro de crisis aguda que presentaba la economía en 1984 llevó al gobierno recientemente electo a lanzar un programa de cambio económico drástico, que condujo en pocos años al país a convertirse en una de las economías más liberalizadas del mundo.

En el marco de estos cambios, el sistema financiero, que constituía una de las esferas más reguladas de la economía, ha pasado a ser uno de los menos reglamentados del planeta. El interés de las reformas neozelandesas reside en su aparente éxito, así como en su carácter rápido y profundo. En el ámbito financiero, a pesar de algunos problemas iniciales, han logrado evitar una crisis financiera abierta.

Este artículo se propone analizar las reformas neozelandesas, así como su impacto sobre la esfera financiera. Para ello, presenta en una primera sección los antecedentes del sistema financiero y las reformas aplicadas; en una segunda sección, caracteriza de manera general las transformaciones producidas por estas reformas, mientras que en una tercera parte se abordan aspectos específicos de la problemática actual de la esfera financiera neozelandesa que pudieran resultar riesgosos en el futuro, como el alto endeudamiento bancario de las familias, su bajo nivel de ahorro y la elevada dependencia del financiamiento externo, así como la alta 
proporción de propiedad extranjera de los intermediarios financieros.

\section{Antecedentes e introducción de las reformas: 1980-1990}

Antes de las reformas liberalizadoras, el sistema financiero de Nueva Zelanda era de tipo "especializado", pues las distintas instituciones financieras ofrecían instrumentos específicos y ejercían funciones bien definidas y acotadas con las cuales las demás no podían legalmente competir. Los intermediarios eran objeto de reglamentaciones y controles típicos de un cuadro de "represión financiera". Cabe recordar que esta clase de medidas habían estado en boga en muchas economías, tanto desarrolladas como en desarrollo; habían sido introducidas en el periodo comprendido entre la crisis de los años treinta y la inmediata posguerra con motivos de precaución y/o de fomento de la inversión productiva y del desarrollo, pero existía una percepción creciente de los costos directos e indirectos que implicaban para el crecimiento económico. En este marco, la política monetaria se establecía por medio de instrumentos directos que incluían controles aplicados a las tasas de interés nominales y requisitos de reserva legal obligatoria; éstos obligaban a las instituciones, en especial a los bancos, a adquirir bonos emitidos por el gobierno con tasas de rendimiento bajas. Los mecanismos de crédito dirigido o selectivo que determinaban las prioridades en la asignación de los préstamos bancarios y procuraban limitar ciertos tipos de crédito, como el crédito al consumo, completaban el dispositivo. Este sistema buscaba elevar el crédito orientado hacia usos seleccionados, incluido el financiamiento a bajo costo del déficit fiscal, y a la vez limitar el impacto inflacionario de este financiamiento al evitar una excesiva demanda de fondos. Estaba complementado por controles cambiarios y de capitales que procuraban aislar a la esfera financiera local de los mercados financieros internacionales, con el objetivo de evitar las salidas de fondos en búsqueda de mejores rendimientos.

En 1984 el sistema financiero neozelandés contaba con cuatro bancos comerciales - tres de los cuales eran de propiedad extranjera-, bancos de ahorro y otras instituciones financieras no bancarias tales como corporaciones financieras o sociedades constructoras. Varias instituciones financieras importantes eran propiedad del gobierno: entre ellas cuatro bancos, que incluían un banco comercial, el Banco de Nueva Zelanda (Bank of New Zealand, BNZ) - nacionalizado en 1946-, dos instituciones de desarrollo, el Banco Rural (Rural Bank) y la Corporación Financiera de Desarrollo (Development Finance Corporation), y el Banco de Ahorro de la Oficina de Correos (Post Office Savings Bank, o PostBank). ${ }^{1}$ Las instituciones financieras públicas comprendían asimismo una hipotecaria (Housing Corporation), una aseguradora de riesgos generales y una aseguradora de vida, creadas a finales del siglo XIX.

Las reglamentaciones más estrictas y los más altos requisitos de reserva legal a los que se hallaban sometidos los bancos habían debilitado su posición competitiva frente a las demás instituciones, produciéndose un proceso de desintermediación, es decir, de migración de los depósitos hacia intermediarios menos regulados. Las autoridades procuraron contrarrestar este movimiento incorporando más instituciones en los requisitos de reserva legal, lo cual contribuyó a volver el sistema más complejo e impredecible. El grado de riesgo de estos intermediarios era sin embargo más elevado, lo cual quedó demostrado en la década 
de los setenta, cuando varios colapsaron o causaron pérdidas a sus depositantes. ${ }^{2}$

En varias oportunidades el gobierno había levantado los controles de tasas de interés y de crédito, pero, en ausencia de equilibrio fiscal, la posterior aceleración inflacionaria y el desequilibrio creciente de la balanza de pagos habían causado su rápida reintroducción. ${ }^{3}$ En 1984 el cambio de gobierno se dio en el marco de una crisis profunda y de salidas de fondos que ocasionaron un colapso del mercado cambiario y demostraron la creciente inoperancia de los controles de capitales. Estas circunstancias favorecieron la introducción de un cambio de rumbo general en la política económica. Ahora bien, el ejemplo neozelandés de reforma económica resulta interesante a más de un título: en primer lugar, por el alcance de las reformas, que hicieron de la economía del país una de las más liberalizadas del planeta, y en segundo lugar por el orden de introducción de las reformas. En efecto, en Nueva Zelanda la secuencia de la liberalización ha sido distinta de lo comúnmente recomendado en la literatura sobre este tema: el cambio en la política monetaria y la liberalización del sistema financiero y de la cuenta de capitales de la balanza de pagos han sido introducidos en forma temprana, sin que se cumpla la condición de equilibrio fiscal a menudo mencionada como un requisito imprescindible para optimizar el proceso de estabilización y de cambio estructural. La adopción de esta secuencia peculiar ha sido justificada sobre la base de argumentos de economía política de las reformas: la liberalización del sistema financiero, más fácil de emprender técnica y políticamente, habría señalado la capacidad y la voluntad del gobierno de liberalizar otros sectores de la economía, facilitando la introducción de los demás aspectos, más difíciles y políticamente costosos, de las reformas. ${ }^{4}$

En el ámbito financiero las reformas implicaron el rápido abandono de los controles y la adopción de un enfoque liberal. Las principales medidas de liberalización incluyeron en 1984-1985 la eliminación de la fijación de las tasas de interés y del sistema de reserva legal obligatoria, y por lo tanto de las compras compulsivas de bonos públicos. La política monetaria pasó a ser indirecta y a depender de la realización de operaciones de mercado abierto. Entre 1984 y 1987 los mecanismos de crédito dirigido fueron abolidos, así como los controles cambiarios y de capitales. Se permitió establecer los contratos en otras monedas diferentes del dólar neozelandés, autorizando de hecho cierta competencia entre monedas, sin que ello permita la circulación de otras divisas en el país. ${ }^{5}$

Un sistema de registro de las instituciones financieras ha sido establecido, $\mathrm{y}$ el modelo elegido para la banca ha sido el de banca múltiple o universal. El sistema ha subrayado la competencia entre instituciones, sin establecer límites al número de bancos autorizados para operar en el país. Como veremos, esto estimuló la entrada de 
nuevos participantes, si bien no ha evitado la prevalencia de condiciones oligopólicas en el sistema bancario.

En 1985 el dólar de Nueva Zelanda empezó a flotar libremente, sin intervención de las autoridades, en un régimen cambiario "puro" adoptado por muy escasos países en el mundo. Esta medida permitió al banco central, el Banco de Reserva de Nueva Zelanda, llevar a cabo una política monetaria independiente de corte monetarista, orientada exclusivamente al control de la inflación, la que autorizó una paulatina disminución del alza de los precios de un ritmo anual superior a 15 por ciento en 1985 a menos de 2 por ciento después de 1991. Los cambios en la política monetaria quedaron plasmados en la nueva Ley del Banco de Reserva, emitida en 1989, que incorpora como objetivo central de su intervención la estabilidad del nivel general de precios; este objetivo debe sin embargo alcanzarse respetando consideraciones de estabilidad del sistema financiero, y puede ser sustituido por otro, establecido por los poderes ejecutivo y legislativo por periodos de menos de 12 meses renovables. ${ }^{6}$ En otras palabras, en caso de necesidad (recesión profunda, situación de guerra), la Ley da cierta flexibilidad para hacer a un lado provisionalmente el objetivo de conservación del poder adquisitivo de la moneda, siempre y cuando el nuevo objetivo sea establecido de manera pública y transparente. Por otro lado, el papel de "banquero del Estado" ha sido eliminado de las actividades a cargo del Banco de Reserva, con el objetivo de evitar confusiones con su rol de gestor de la política monetaria y de garante de la estabilidad del sistema financiero; a partir de 1989 la gestión de los fondos del Estado fue objeto de licitación pública entre los bancos privados. ${ }^{7}$

En 1987 el gobierno inició un proceso de privatización de empresas públicas que incluyó sus participaciones en el sector financiero; en razón de su importancia, cabe señalar la venta del Rural Bank en 1989 y de las actividades financieras de la oficina de correos, PostBank (respectivamente a Magneton Holdings y al grupo ANz) y en 1992 la del banco comercial Bank of New Zealand al banco australiano National Australia Bank (NAB), acompañadas de algunas privatizaciones de menor importancia relativa. ${ }^{8}$

Finalmente, en 1996 se adoptó un nuevo sistema de supervisión bancaria que concede mucho lugar a la autodisciplina y a la disciplina de mercado. Éste incluye entre sus elementos más sobresalientes la adopción de los requisitos de capitalización de Basilea (un capital de por lo menos 8 por ciento de los activos ponderados por su grado de riesgo), un límite a los préstamos realizados a partes relacionadas y el requisito de publicación trimestral de un informe financiero que contenga, entre otros indicadores, el nivel de riesgo de las posiciones asumidas por el banco, así como su desempeño financiero. ${ }^{9}$ Este informe, que debe ser firmado por los miembros del directorio y puesto a la disposición del público en sus sucursales, constituye un elemento importante del dispositivo prudencial. En efecto, la transparencia en la información tiene tanta más importancia para los depositantes que el sistema precautorio neozelandés, que no incluye una "red de seguridad", es decir un mecanismo formal de seguro de depósitos. ${ }^{10}$

\section{Los resultados: evolución del sistema financiero neozelandés desde las reformas}

En la primera mitad de la década de los ochenta el sistema financiero neozelandés era de tamaño reducido (véanse más ade- 
lante las gráficas 1, 2 y 5). Los indicadores de tamaño del sistema bancario, la monetización, medida por la participación de la oferta monetaria (M2) en el producto interno bruto (PIB), (M2/PIB) y el crédito interno medido en relación con el PIB mostraban niveles inferiores a 20 por ciento para el primero y de cerca de 27 por ciento para el segundo. Como producto del proceso de desintermediación mencionado en el apartado anterior, alrededor de 40 por ciento del crédito al sector privado provenía de instituciones competidoras de los bancos comerciales (otras instituciones bancarias, como los bancos de desarrollo o instituciones financieras no bancarias). El mercado accionario era también relativamente pequeño, pues en 1985 su capitalización superaba apenas 30 por ciento del PIB.

El impacto de la liberalización sobre esta esfera financiera poco desarrollada ha sido inicialmente fuerte y su trayectoria posterior a 1985 no ha estado exenta de sobresaltos, atribuidos por numerosos analistas a la secuencia y a la velocidad de las propias reformas. En particular, cabe señalar que tanto la monetización como el crédito interno, ambos indicadores del peso relativo del sistema bancario, se elevaron notablemente entre 1987 y 1989, periodo caracterizado por altas tasas de interés y una disminución de la inflación más lenta de lo esperado: la razón M2/PIB pasó de 22 por ciento en 1987 a 56 por ciento en 1989 , mientras la relativa al crédito interno lo hacía de 32 a 78 por ciento, un crecimiento que parecía demasiado rápido para asegurar la estabilidad del sistema (gráficas 1 y 2).

Las autoridades monetarias argumentaron en el momento que esta evolución no

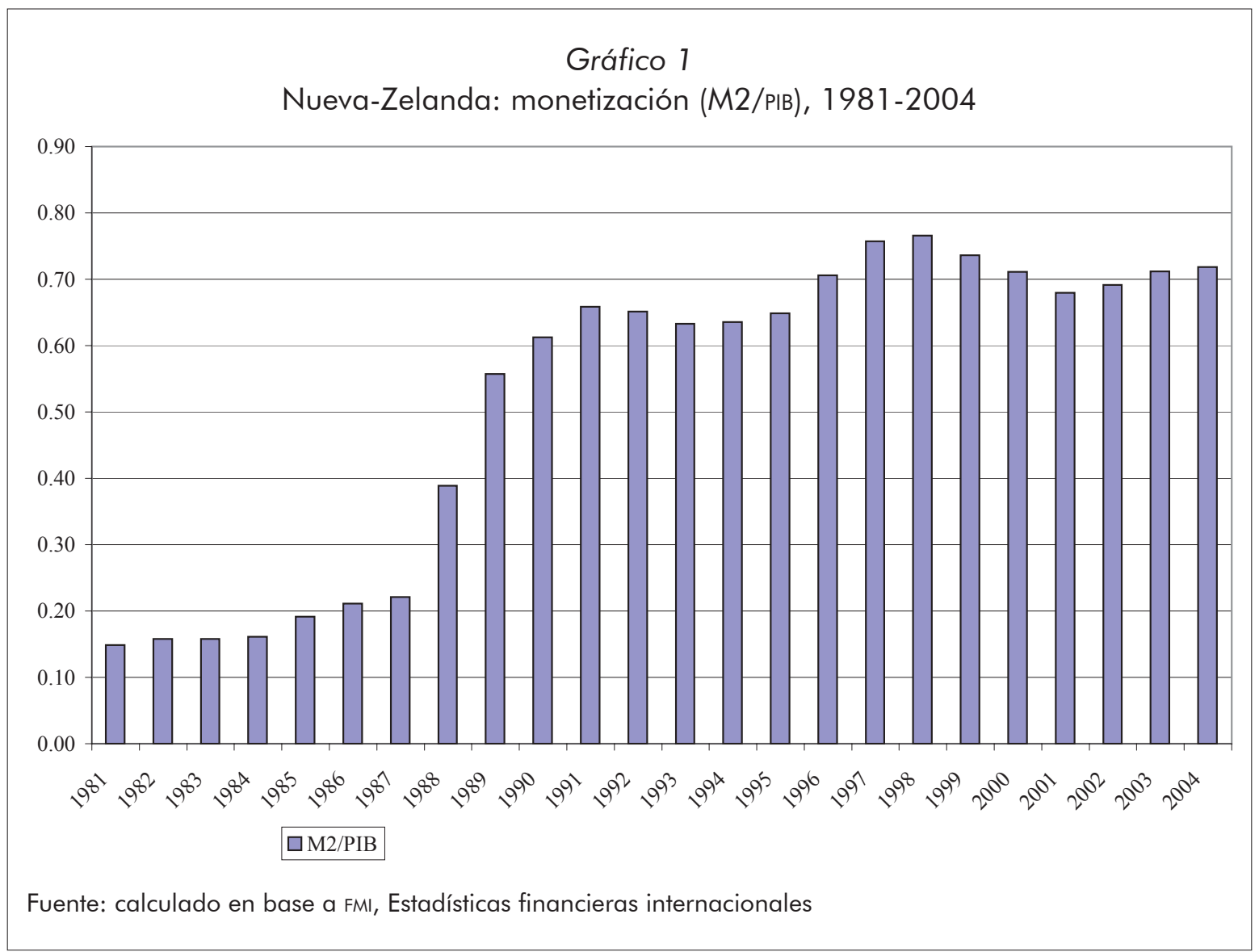


Gráfico 2

Nueva-Zelanda: crédito interno/PIB, 1981-2004

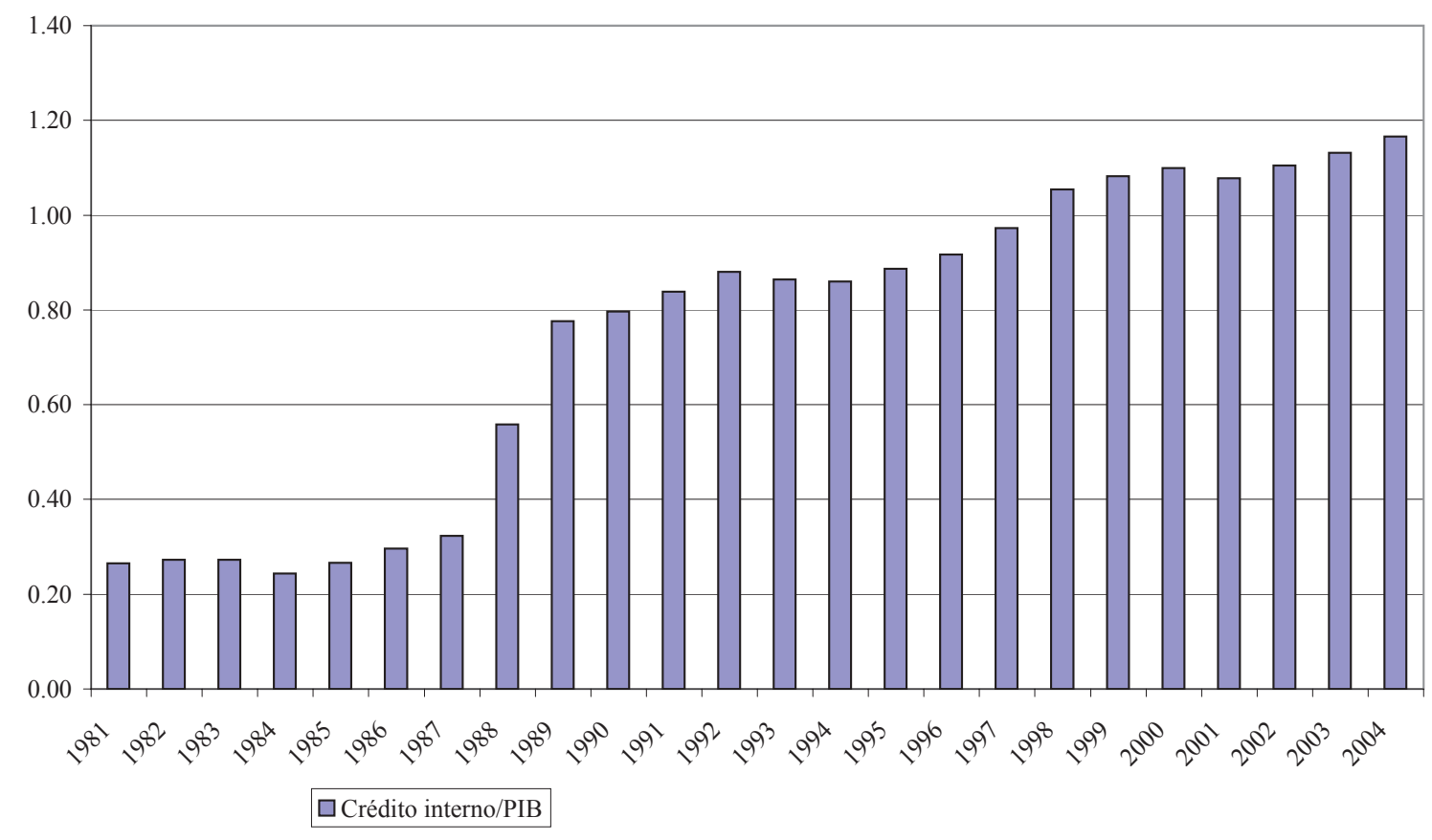

Fuente: calculado en base a FMI, Estadísticas financieras internacionales

era alarmante, pues se debía al proceso de reintermediación bancaria en curso en la economía, es decir que reflejaba el hecho de que los bancos, liberados de su carga de reglamentaciones, recuperaban competitividad y ganaban participación en el sistema a costa de las demás instituciones financieras. Analistas críticos afirmaron, por el contrario, que esta evolución provenía de dificultades en la instrumentación de la política monetaria basada en el control de un agregado monetario estrecho y de la excesiva toma de riesgos por parte de ciertos bancos, que alimentaron un auge especulativo en los precios de los terrenos y en el mercado accionario. ${ }^{11}$ Esta primera etapa de las reformas terminó con un desplome del mercado accionario en 1987 (gráficas 3 y 4): si bien éste se vincula directamente con la ola de crisis internacionales suscitada por el crash de la bolsa estadounidense, tanto el auge como la posterior caída del mercado accionario neozelandés fueron más marcados que en los demás países, lo cual sugiere la presencia de factores internos que contribuyeron a fortalecerlos. Posteriormente el Banco de Reserva adoptó una nueva modalidad de control monetario, abandonando el enfoque centrado en el control cuantitativo de un agregado y se registró un proceso de reestructuración del sistema bancario, que se aborda más adelante en este texto. En suma, si la liberalización financiera neozelandesa ha evitado producir hasta la fecha una crisis sistémica, no ha estado exenta de problemas circunscritos a determinadas instituciones, ni de costos para los ahorradores.

La evolución posterior de los indicadores financieros ha mostrado un crecimiento más estable, que ha llevado a un notable 


\section{Análisis}

\section{Gráfico 3}

Nueva-Zelanda: importancia relativa de los mercados financieros (1985-2003)

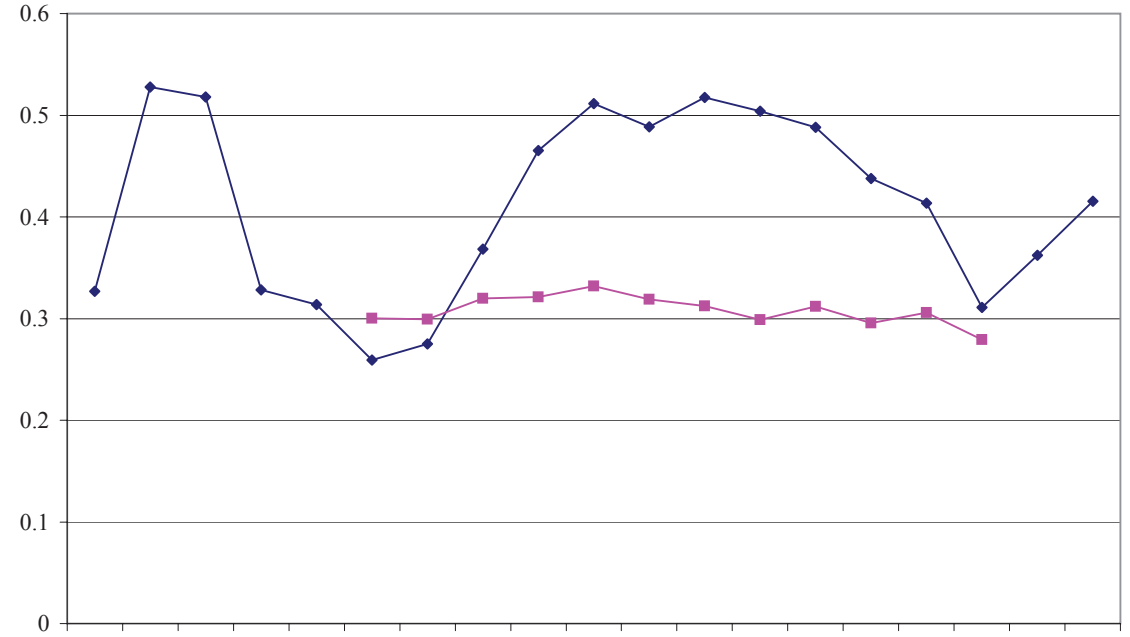

1985198619871988198919901991199219931994199519961997199819992000200120022003

- Capitalización del mercado accionario/PIB

$\rightarrow$ - Valor de mercado de bonos públicos/PIB

Fuente: Banco Mundial, Financial Structures Database y Federación internacional de bolsas de valores.

\section{Gráfico 4}

Nueva-Zelanda: índice de precios del mercado accionario (1980-2003)

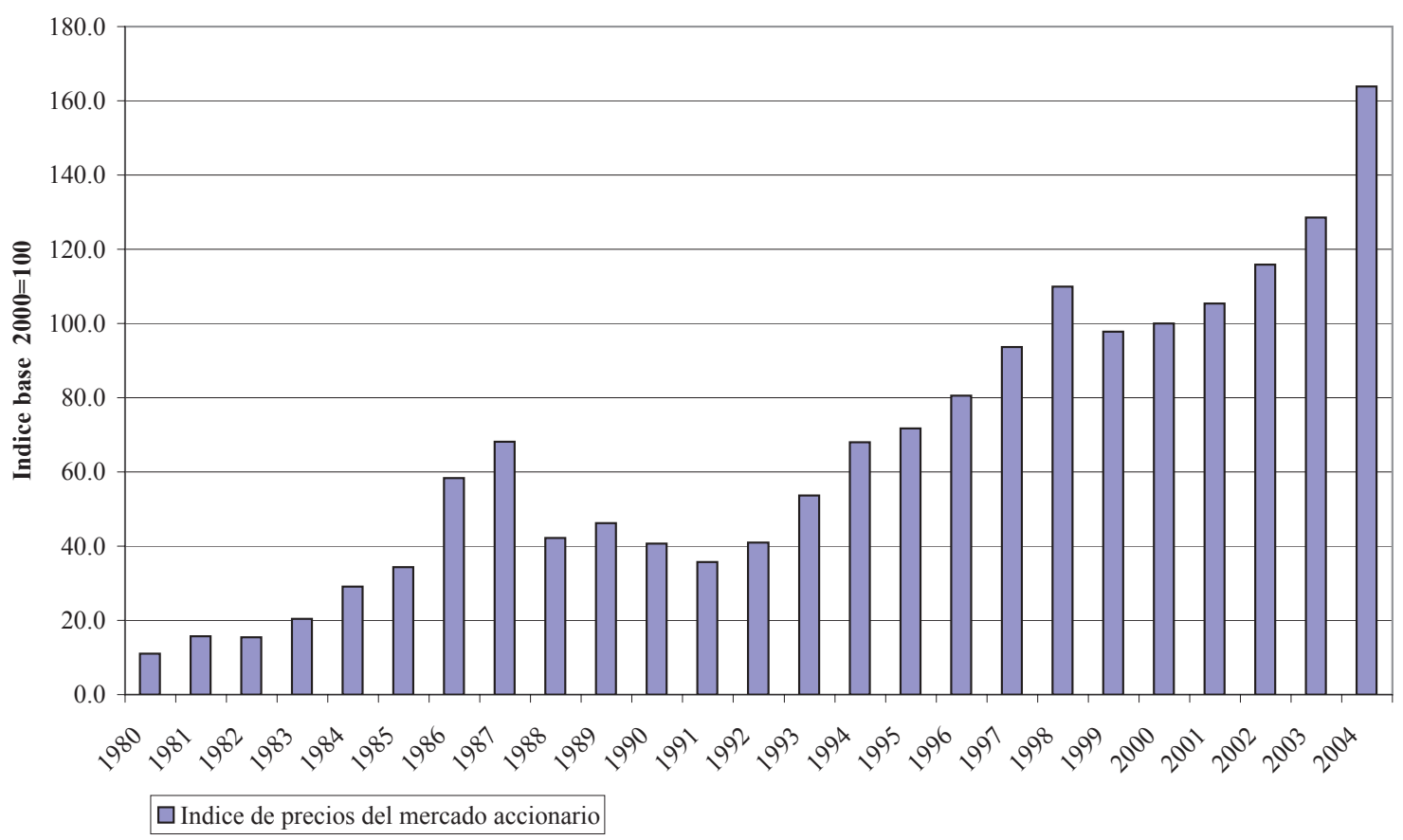

Fuente: calculado en base a FMI, Estadísticas financieras internacionales 
proceso de profundización financiera: en 2004 el agregado monetario M2 alcanzaba 72 por ciento del PIB, mientras que el crédito interno se situaba en 117 por ciento; en otras palabras, el sistema bancario neozelandés tiene en la actualidad un tamaño cuatro veces mayor que antes de las reformas (gráficas 1 y 2 , supra). En cuanto a los mercados de títulos negociables, su evolución ha sido bastante menos dinámica; el mercado de bonos se sigue centrando alrededor de los bonos públicos. Este mercado, el más activo y líquido, mantenía un peso cercano a 30 por ciento del PIв (21.8 miles de millones de dólares neozelandeses - \$NZ - a fines de 2003): la desaparición de los déficit gubernamentales ha reducido las emisiones por parte del Estado. Por otro lado, existen alrededor de 30 emisores corporativos, privados y públicos, en el mercado local, con un valor de bonos de 7.2 miles de millones de $\$$ NZ en el mismo año, y emisiones de bonos "Eurokiwi”, denominados en moneda local pero colocados en el extranjero por un valor de 11.9 miles de millones de $\$$ NZ. ${ }^{12}$

En cuanto al mercado de valores, después de una prolongada postración (19861991) sólo había recuperado su tamaño relativo en 1996, antes de la crisis asiática (una capitalización bursátil de 51.7 por ciento del PIB en este año contra 52.7 por ciento en 1986), y se situaba en 2003 a un nivel relativamente bajo: 41.7 por ciento del PIB. Este desempeño modesto de los mercados se puede atribuir a diversos factores combinados. Del lado de la oferta, el tamaño pequeño de la mayoría de empresas neozelandesas hace que los costos de financiamiento directo en los mercados sean para ellas excesivos, reduciendo el número de emisores potenciales. Del lado de la demanda, se menciona la preferencia de los ahorradores por la inversión inmobi-

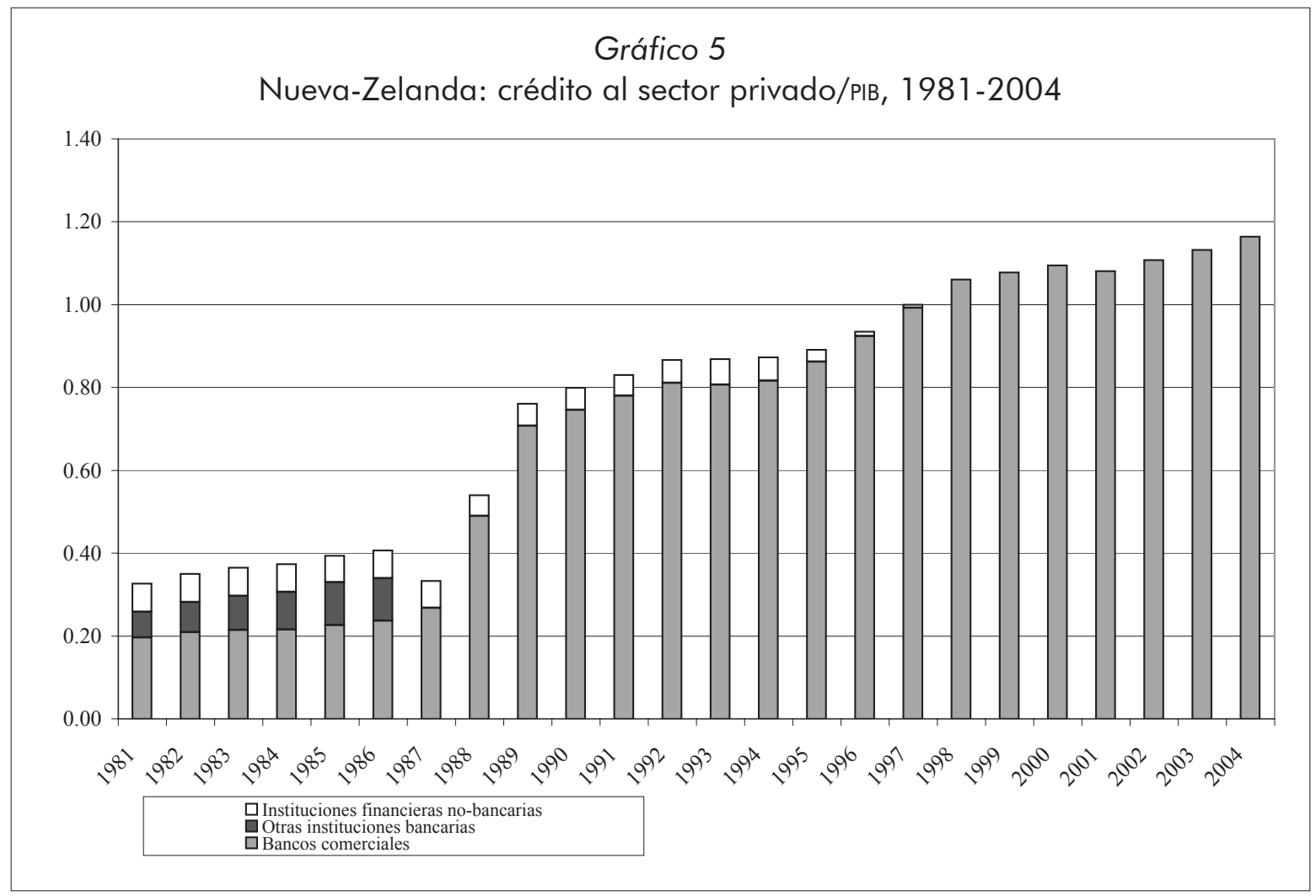


liaria, y el nivel relativamente bajo de sus inversiones financieras; de hecho, una parte importante de los títulos se intercambia fuera del país y figura en el portafolio de inversionistas extranjeros. En suma, como lo precisamos en lo que sigue, el proceso de profundización financiera neozelandesa ha sido sobre todo producto de la expansión de los grandes bancos, y no de otros intermediarios o de los mercados financieros.

La gráfica 5, que señala el impacto de las reformas sobre el crédito al sector privado, proporciona una primera indicación del poder adquirido por los grandes bancos universales a partir de las reformas: las otras instituciones bancarias y financieras, las cuales incluían entidades públicas de fomento, que concedían alrededor de 40 por ciento del crédito al sector privado entre 1980 y 1986, redujeron su contribución entre 1987 y 1996, mientras el crédito bancario se elevó de 27 por ciento del PIB a 116 por ciento en 2004, volviéndose los bancos registrados proveedores de la gran mayoría del crédito al sector privado.

La desreglamentación ha inducido inicialmente un proceso de consolidación de bancos de ahorro e instituciones financieras no bancarias, así como la entrada de nuevos competidores al sistema bancario, algunos provenientes de los rangos de las instituciones financieras no bancarias. Un posterior proceso de reestructuraciones y fusiones bancarias llevó el número de bancos registrados a 19 en 1998, 18 en 2002 y 16 en 2004, con la reciente fusión de dos bancos universales de importancia sistémica, los bancos ANZ y National Bank. ${ }^{13}$ En 2002 la estructura del sistema financiero neozelandés mostraba la preeminencia de los bancos, que concentraban una proporción creciente de los activos: 70 por ciento en 2000, 73.6 por ciento en 2002 (véase cuadro 1) y 74.5 por ciento en 2003 según datos del Banco de Reserva de Nueva Zelanda para ese año. ${ }^{14}$ Los fondos de inversión venían

\section{Cuadro 1}

Nueva-Zelanda: estructura del sistema financiero, 2000-2002

(a fines de período)

\begin{tabular}{lrrrr}
\hline & número de instituciones & \multicolumn{2}{c}{ en \% de los activos totales } \\
\hline & 2000 & 2002 & 2000 & 2002 \\
\hline Bancos & 18 & 17 & 70.7 & 73.6 \\
Locales & 1 & 2 & 0.5 & 0.8 \\
Subsidiarias de propiedad extranjera & 11 & 10 & 25.2 & 24.9 \\
Corporaciones locales de propiedad extranjera & 6 & 5 & 45 & 47.8 \\
Otras instituciones financieras & 311 & 290 & 29.3 & 26.4 \\
Fondos de inversión & 56 & 56 & 18.7 & 16 \\
Aseguradoras de vida & 39 & 36 & 4.9 & 3.8 \\
Otras aseguradoras & 85 & 75 & 1.5 & 1.3 \\
Compañías financieras & 46 & 50 & 2.4 & 3.3 \\
Compañías constructoras & 10 & 11 & 0.9 & 1 \\
Uniones de crédito & 74 & 61 & 0.2 & 0.1 \\
Fideicomisos de bonos bonus & 1 & 1 & 0.8 & 0.9 \\
Total sistema financiero & 329 & 307 & 100 & 100 \\
\hline
\end{tabular}

Fuente. FMI, Country Report n 04/126, Washington DC, mayo de 2004, cuadro 4, p. 11. 
Cuadro 2

Bancos registrados en Nueva-Zelanda, Septiembre de 2004

\begin{tabular}{lccc}
\hline Nombre del banco & \% del mercado & País de origen de la matriz & $\begin{array}{c}\text { Calificación } \\
\text { (S\&P) } 7 /\end{array}$ \\
\hline Bancos de importancia sistémica & & & AA- \\
ANZ National Bank Limited & 33.9 & Australia & AA- \\
Westpac Banking Corporation & 20.1 & Australia & AA- \\
Bank of New Zealand & 17 & Australia & AA- \\
ASB Bank Limited & 14.1 & Australia & \\
Total & 85.1 & & AA- \\
Otros bancos & & & - \\
Deutsche Bank A.G. & 6.7 & Alemania & AAA \\
Hong Kong and Shanghai Banking Corp. & 2.8 & Reino Unido & AA \\
Rabobank New Zealand Limited & 1.4 & Países Bajos & BBB- \\
Citibank N.A. & 1 & Estados Unidos & AA- \\
TSB Bank Limited & 1 & Nueva-Zelanda & AA- \\
Commonwealth Bank of Australia & 0.9 & Australia & AAA \\
Kiwibank Limited & 0.5 & Nueva-Zelanda & AA- \\
Rabobank Nederland & 0.3 & Países Bajos & A- \\
ABN AMRO Bank NV & 0.2 & Países Bajos & BBB+ \\
Bank of Tokyo-Mitsubishi Limited & 0.1 & Japón & BBB- \\
Kookmin Bank & 0.1 & Corea del Sur & Australia/Nueva-Zelanda \\
St George Bank New Zealand Limited & 0.1 & & \\
\hline
\end{tabular}

1/ Calificación otorgada por la calificadora de valores estadounidense Standard \& Poor's Fuente: RBNZ, Financial Stability Report, octubre de 2004, table A3, p. 41.

en segundo lugar con 16 por ciento de los activos del sistema. Las demás instituciones de intermediación (compañías financieras, uniones de crédito y compañías constructoras) eran de tamaño más pequeño, pero su crecimiento, en particular en el caso de las compañías financieras y de las constructoras, ha venido acelerándose desde fines de los noventa, en la medida en que han empezado a servir nichos no atendidos por los bancos, en especial en los mercados de crédito al consumo e hipotecario. ${ }^{15}$

Los bancos que dominan el sistema financiero neozelandés forman a su vez un sistema bastante concentrado, donde destacan cuatro grandes instituciones de importancia sistémica; ${ }^{16}$ éstas representaban 85 por ciento de los activos del sistema bancario, con 33 por ciento del total de éstos para el primer banco. Las demás instituciones son en general pequeñas y dedicadas a nichos de mercado específicos: nueve de ellas tenían en conjunto poco más de 4 por ciento de los activos del sistema (véase cuadro 2). Esta configuración del sistema bancario ha suscitado inquietudes relativas a un excesivo poder de mercado de las grandes instituciones, es decir, al potencial para el surgimiento de un monopolio u oligopolio no competitivo, con consecuencias dañinas para los clientes del sistema. ${ }^{17}$ Por otro lado, el proceso de reestructuración de las redes bancarias ha implicado el cierre de numerosas sucursales, estimadas en cerca de 700 entre 1994 y $2002 .{ }^{18}$ Estos desarrollos llevaron al gobierno a confiar de nuevo a la Oficina de Correos un papel financiero mediante 
la creación controvertida de un nuevo banco, Kiwibank, ${ }^{19}$ que utiliza las agencias postales para establecer sus sucursales $\mathrm{y}$ atender comunidades que se quedaron sin agencia bancaria, o constituirse en un competidor para los grandes bancos comerciales extranjeros instalados en la plaza, acusados de cobrar intereses y comisiones más altos que en sus mercados de origen. Ahora bien, la participación de Kiwibank en los activos del sistema es modesta (0.5 por ciento de los activos en 2004), como lo es la de las escasas instituciones en mano de capitales neozelandeses (véase cuadro 2), pero ha logrado captar una clientela suficiente para cumplir su objetivo de rentabilidad a los tres años de fundado, y ha agregado en 2004 servicios destinados a los negocios a su rango de actividades orientadas hacia las familias. ${ }^{20}$

El predominio casi absoluto de entidades extranjeras constituye un rasgo sobresaliente del sistema financiero neozelandés actual. Esta presencia ya era importante antes de la liberalización, pues tres de los cuatro bancos comerciales eran de propiedad foránea, pero se ha elevado sensiblemente desde el inicio de las reformas. Actualmente Nueva Zelanda es una de las economías del mundo con mayor presencia extranjera en los servicios financieros: de los 16 bancos presentes en el mercado, 14 son extranjeros, con casas matrices ubicadas en diversas naciones, y en particular en Australia en el caso de los cuatro bancos de importancia sistémica. Es también el caso de las instituciones financieras no bancarias de mayor tamaño, a menudo subsidiarias de bancos extranjeros. Basándose en datos publicados por los bancos en sus informes Tripe estima que, desde 1996, 99 por ciento de activos del sistema financiero neozelandés están bajo control extranjero. ${ }^{21}$ Como lo veremos en el apartado siguiente, estas características no están exentas de problemas, en especial en materia de supervisión prudencial y en razón de su relación con la balanza de pagos del país.

\section{Riesgos y perspectivas}

Los riesgos que se perciben en la actualidad en el sistema financiero neozelandés a 20 años del inicio de las reformas, son de tres tipos. Se relacionan en primer lugar con el creciente endeudamiento bancario de las familias y su bajo nivel de ahorro; en segundo lugar con el impacto del fondeo bancario en la balanza de pagos y, finalmente, con la supervisión y la protección de un sistema en el que predominan bancos extranjeros.

El alto y creciente endeudamiento familiar es consecuencia de la desregulación financiera, y en particular de la eliminación del crédito dirigido. En Nueva Zelanda, al igual que en otros países donde el Estado intervenía activamente en la asignación de recursos, las razones de deuda bancaria de las familias en relación con su ingreso eran bajas. Se favorecía el financiamiento de las actividades productivas, y en particular, en el caso de Nueva Zelanda, la agricultura, en desmedro de otros usos del crédito. Después de la liberalización, el rápido crecimiento del crédito ha sido dirigido hacia las actividades o usos previamente "desatendidos", y en especial hacia el crédito al consumo y el hipotecario. El cuadro 3 señala la fuerza de esta reorientación: entre 1985 y 2000 los préstamos a la industria y al comercio crecieron en 141 por ciento, los préstamos a las familias en 196 por ciento, mientras que el crédito a la agricultura sólo lo hacía en 15 por ciento, después de una prolongada contracción.

Como resultado de estas trayectorias divergentes, que muestran la cada vez más 
Cuadro 3

Nueva-Zelanda: tasas de crecimiento real del crédito por sectores, 1985-2000*

\begin{tabular}{lccc}
\hline Sectores & $1985-1990$ & $1985-1995$ & $1985-2000$ \\
\hline Agricultura & -38 & -8 & 15 \\
$\begin{array}{l}\text { Industria y } \\
\text { comercio }\end{array}$ & 76 & 80 & 141 \\
$\begin{array}{l}\text { Crédito total } \\
\text { a sectores }\end{array}$ & 40 & 51 & 101 \\
productivos & & & \\
$\begin{array}{l}\text { Familias } \\
\text { Crédito total }\end{array}$ & 36 & 103 & 196 \\
\hline
\end{tabular}

*tasas acumuladas calculadas en relación con el nivel alcanzado en 1985.

Fuente: Thorp. Clive, "Developments in credit markets over two decades", RBNZ Bulletin, vol. 65, n² 2, junio de 2002 (1980 y 1990), disponible en http://rbnz. govt.nz/research/bulletin/2002_2006/2002jun65_ 2thorp.pdf.

marcada preferencia de los bancos por el crédito a las personas, una parte sustancial de los activos bancarios se encuentra ahora constituida por préstamos hipotecarios residenciales; así, en lo que concierne a los cuatro mayores bancos (85 por ciento de los activos bancarios), la cartera de crédito representaba 83 por ciento de sus activos y estaba constituida a la altura de 52 por ciento por préstamos hipotecarios (véase cuadro 4). En suma, tanto las familias como las empresas han elevado notablemente sus montos de endeudamiento, pero la cartera de crédito bancario está ahora más enfocada hacia las primeras. Ahora bien, ¿es riesgosa para el sistema está concentración en el crédito hipotecario? A menudo, la liberalización financiera ha producido este patrón de asignación de recursos por parte de los bancos, el cual ha sido considerado de riesgo - con frecuencia a posteriori-, en la medida en que ha ido alimentando una "burbuja" inmobiliaria y, cuando ésta estalla, una elevación fuerte de los créditos impagables.

Tanto las autoridades neozelandesas como los organismos financieros multilaterales como el FMI, coinciden en considerar que la situación no presenta actualmente riesgos excesivos. Para el banco central neozelandés, la concentración en el crédito hipotecario habría incluso disminuido la exposición al riesgo de los bancos, debido a los montos individuales menores de este tipo de crédito y a que las familias reciben sus ingresos de una variedad de sectores económicos, lo cual permite, en relación con el préstamo comercial o industrial, disminuir la exposición al riego sectorial de la cartera agregada. ${ }^{22}$ Por otro lado, se subraya que la carga de intereses soportada por las familias es todavía bastante llevadera, que las empresas neozelandesas tienen cocientes de endeudamiento aceptables, en especial si se considera el papel central que desempeña el crédito bancario en su financiamiento externo, y que los bancos presentan un buen nivel de rentabilidad, una bajísima proporción de préstamos de mala calidad, son adecuadamente capitalizados (cuadro 4) y han recibido calificaciones internacionales de buen nivel (cuadro 2).

Cabe sin embargo señalar que esta buena situación le debe mucho al buen desempeño de la economía en los últimos años, y recordar que rara vez es en tiempos de bonanza económica sino durante los procesos de desaceleración del crecimiento, cuando aparecen los problemas y se multiplican los créditos incobrables. Por esta razón, la situación de las familias es estudiada más de cerca, pues se estima que es allí donde se podrían presentar problemas para la banca. En efecto, su hoja de balance muestra el proceso de endeudamiento al que han recurrido las familias neozelandesas desde mediados de los ochenta, siguiendo la baja en las tasas de interés y la desregulación: sus pasivos financieros, que no sobrepa- 
Cuadro 4

Nueva-Zelanda: indicadores bancarios, $2004 / 1$

\begin{tabular}{lr}
\hline Activos (en \% del total) & 10.2 \\
\hline Inversiones financieras & 42.9 \\
Préstamos hipotecarios & 39.3 \\
Otros préstamos & 7.7 \\
Otros activos & \\
Indicadores de rentabilidad (promedio anual) & 2.6 \\
Margen de interés & 1.3 \\
Rentabilidad sobre activos promedio & \\
Medidas de capitalización & 10.4 \\
Total & 7.9 \\
Tier 1 & 0.2 \\
Activos de mala calidad (en \% de préstamos & \\
totales) &
\end{tabular}

$1 /$ Cuatro bancos de importancia sistémica Fuente. FMI, Country Report n ${ }^{\circ}$ 05/152, Washington DC, mayo de 2005, anexo 1, p. 33.

saban la mitad de su ingreso disponible anual en 1980, alcanzaban en 2004130 por ciento de esta variable, con 109 por ciento sólo para los préstamos hipotecarios (cuadro 5). Su nivel de ahorro, calculado como porcentaje del ingreso corriente, que era de cerca de 13 por ciento a inicios de los ochenta, ha caído estrepitosamente con la liberalización financiera; en 1996 era apenas de 1.5 por ciento del ingreso y es ahora negativo: -4 por ciento en 1998 y -8.2 por ciento en 2004 . Ahora bien, a pesar de este desplome del ahorro, la riqueza neta familiar ha ido al alza: de 292 por ciento de su ingreso disponible anual en 1980 a 431 por ciento en 2004. Este fenómeno sólo es paradójico en apariencia, pues la riqueza neta incorpora las ganancias de capital: la fuerte alza del precio de las viviendas ${ }^{23}$ —sólo hubo un retroceso entre 1989 y 1993 - que ha valorizado el patrimonio inmobiliario, que constituye la parte más importante de la riqueza familiar (197 por ciento del ingreso disponible anual en 1980 y 387 por ciento en 2004); es probable que este "efecto-riqueza" explique en parte la caída del ahorro.

Ahora bien, ¿qué pasaría en caso de desaceleración económica o de alza sensible de

Cuadro 5

Nueva-Zelanda: indicadores de hoja de balance familiar, 1998-2004 (en \% del ingreso disponible anual)

\begin{tabular}{lllll}
\hline & 1980 & 1990 & 1998 & 2004 \\
\hline Riqueza neta & 292 & 358 & 373 & 431 \\
Riqueza financiera neta & 95 & 101 & 161.6 & 153 \\
Activos & 144 & 168 & 178 & 176 \\
Pasivos 1/ & 49 & 64 & 16.4 & 23 \\
Riqueza inmobiliaria neta & n.d. & n.d. & 212.4 & 278 \\
Valor de las viviendas & 197 & 257 & 296 & 387 \\
Préstamos hipotecarios & n.d. & n.d. & 83.6 & 109 \\
Costos de servicio de la deuda & n.d. & n.d. & 8.5 & 9.5 \\
Tasa de ahorro & n.d. & n.d. & -4 & -8.2 \\
\hline
\end{tabular}

1/ Los datos para 1980 y 1990 incluyen los préstamos hipotecarios.

Fuentes. Thorp. Clive, "Developments in credit markets over two decades", RBNZ Bulletin, vol. 65, n² 2, junio de 2002 (1980 y 1990), disponible en http://rbnz.govt.nz/research/bulletin/ 2002_2006/2002jun65_2thorp.pdf; FMI, Country Report n 05/152, Washington DC, mayo de 2005 , anexo 1, p. 34 (1998 y 2004). 
las tasas de interés? ¿Podrían las familias neozelandesas seguir sirviendo su deuda, o los préstamos incobrables pondrían en riesgo la estabilidad de los bancos? Algunos análisis realizados por el Banco de Reserva o por el FMI tratan de evaluar el impacto de futuros cambios en éstas y en otras variables económicas sobre la situación financiera de las familias; en efecto, si el servicio de la deuda familiar no ha presentado problemas hasta la fecha, ha ido en aumento, hasta alcanzar 10.4 por ciento del ingreso disponible a fines de 2004. Se estima que un aumento de 1 por ciento de las tasas de interés de los préstamos hipotecarios elevaría estos costos financieros a 11.5 por ciento del ingreso disponible. ${ }^{24}$ Como consecuencia, es muy probable que el consumo familiar se haya vuelto más sensible a modificaciones en las tasas de interés y se vería negativamente afectado por su elevación, en particular porque los contratos hipotecarios en el país incorporan rápidamente estas alzas: 26 por ciento son a tasas flotante y 60 por ciento a tasas fijas revisables a periodos de dos años. ${ }^{25}$ De hecho, un ejercicio econométrico de simulación muestra que, con los niveles actuales de deuda familiar, el impacto de un alza de 1 por ciento en las tasas de interés produciría una disminución de 2.3 por ciento del consumo en un plazo de ocho trimestres. ${ }^{26}$

Se puede esperar un efecto similar de una caída en los precios de las viviendas que reduciría la riqueza neta de las familias neozelandesas. Por otro lado, un nivel más alto de riqueza neta familiar, como el que existe ahora en el país, podría facilitar la contratación de préstamos que permitan suavizar el impacto de estos cambios sobre el consumo inmediato, como lo mostraría el caso de Estados Unidos. ${ }^{27}$ En todo caso, resulta claro que el impacto macroeconómico de estos cambios sería significativo y que el sistema bancario se vería afectado. En un estudio reciente el Banco de Reserva de Nueva Zelanda indica que tal vez no lo sería directamente, es decir mediante una elevación de la proporción de créditos hipotecarios vencidos, sino de manera indirecta, en razón del efecto de la caída de los gastos de consumo sobre la rentabilidad de las empresas y, por ende, sobre su capacidad de servir su deuda bancaria. ${ }^{28}$

Por otra parte, la cuestión del ahorro privado debe ser considerada también bajo el ángulo de la balanza de pagos. En efecto, aun cuando son parcialmente compensados por un elevado ahorro público, los bajísimos niveles de ahorro familiar traen como consecuencia un bajo nivel de ahorro agregado para la economía en su conjunto y la necesidad del financiamiento externo. Nueva Zelanda presenta déficit crónicos en su cuenta corriente, y éstos no han desaparecido con las reformas. En 2004 la cuenta corriente presentaba un saldo negativo de -6.4 por ciento del PIB y los pasivos externos netos alcanzaban 84.5 por ciento. Por otro lado, desde 2003 el dólar neozelandés se ha ido revaluando significativamente, en particular en relación con el dólar de Estados Unidos, una evolución asociada al alto nivel actual de los términos de intercambio del país y al diferencial de tasas de interés positivo. ${ }^{29}$

En razón del alto nivel de desarrollo de la economía neozelandesa, de su buen desempeño y del nivel más elevado de las tasas de interés internas, el déficit se ha financiado con holgura. Ahora bien, la composición del endeudamiento externo se ha modificado en años recientes, para depender en mayor proporción del sistema bancario. En efecto, en los últimos años los bancos más que duplicaron su deuda externa, que pasó de 25 por ciento del PIB en marzo de 1997 a 59 por ciento en marzo 
de 2004, estableciéndose este año su participación en la deuda externa bruta a 57 por ciento del total. ${ }^{30}$ En las operaciones del sistema bancario interno se observa una correspondiente modificación de las fuentes de fondeo de los intermediarios. La participación de los depósitos e inversiones de las familias - una fuente más barata y estable de fondos - ha ido cayendo de 39 por ciento en 1990 a 23 por ciento en 2003, elevándose por el contrario el fondeo internacional de 15 a 28 por ciento del total (gráfico 6). Esta modificación en las fuentes del endeudamiento externo tuvo como consecuencia adicional un acortamiento de los plazos de contratación, fenómeno característico del fondeo bancario.

Por otro lado, el papel del sistema bancario es también central en la explicación del déficit actual de la cuenta corriente: éste proviene esencialmente de la subcuenta de ingresos, que captura los flujos relacionados con inversiones; una estimación reciente establece que en junio de 2003, 62.28 por ciento del déficit neto de esta subcuenta era atribuible al sistema bancario por diferentes conceptos, como las utilidades remitidas y el servicio de la deuda externa. ${ }^{31}$ En otras palabras, los bancos de propiedad extranjera explican las elevadas necesidades de financiamiento externo, a la vez que intermedian una gran parte de los flujos financieros que ingresan al país.

Los riesgos potenciales de una importante participación del crédito internacional de corto plazo en el financiamiento externo, que han sido puestos en evidencia en las crisis financieras que golpearon a varias economías en desarrollo importantes en la década de los noventa, surgen de su carácter volátil, y del impacto de variaciones bruscas en el tipo de cambio, que dañarían la capacidad de pago en divisas de los acreditados locales. De hecho, algunos autores mencionan que el país podría estar expuesto al riesgo de una crisis de balanza de pagos o una crisis gemela que partiría

\section{Gráfico 6}

Nueva-Zelanda: fondeo bancario por tipo de fuentes, 1990-2003

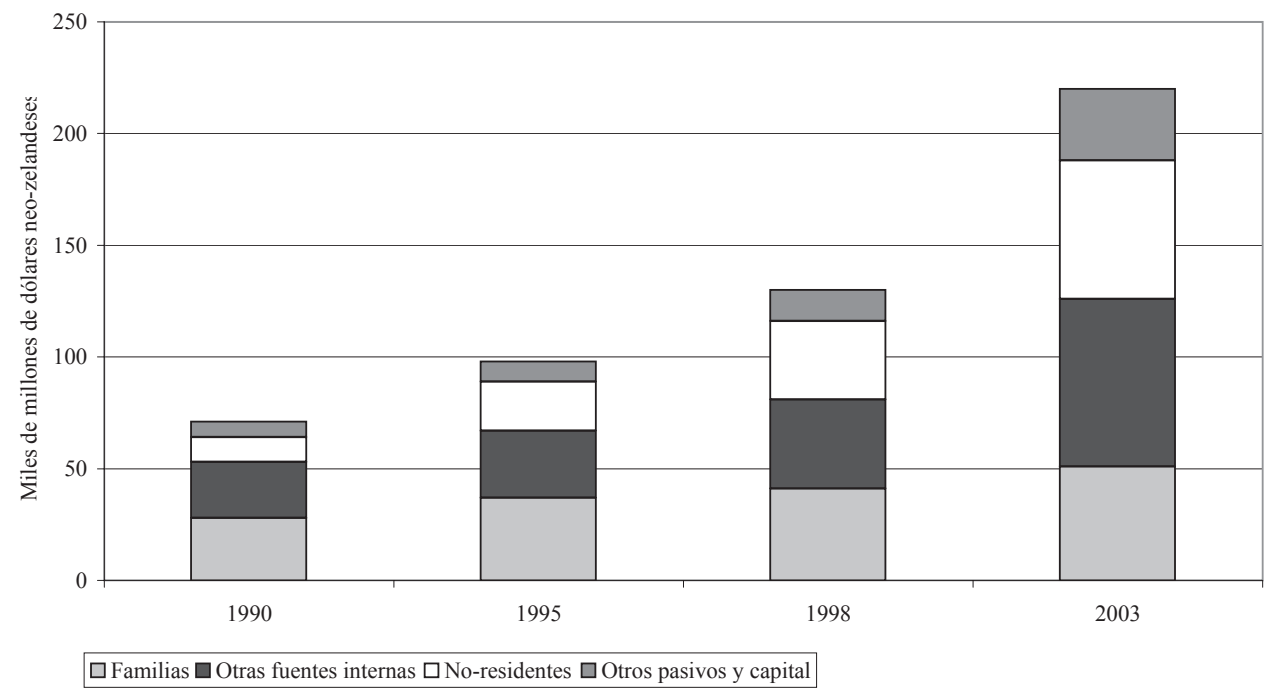

Fuente: RBNZ, Financial Stability Report, octubre de 2004, cuadro A1 p. 40. 
del sistema bancario. ${ }^{32}$ Ahora bien, varias características de estos créditos internacionales contribuyen a disminuir, tal vez en forma sensible, estos riesgos en el caso de Nueva Zelanda. En primer lugar, porque los créditos son en parte canalizados por los bancos matrices australianos hacia sus sucursales o subsidiarias neozelandesas; esto contribuye a reducir, en principio, el riesgo de no renovación de créditos revolventes. Para los créditos contratados directamente en los mercados internacionales al por mayor, se espera que la fortaleza del banco australiano matriz contribuya a garantizar la banca neozelandesa. ${ }^{33}$ En segundo lugar, el riesgo cambiario de estas operaciones es menor, pues la mitad de esta deuda es contratada en moneda nacional y la fracción contratada en divisas está casi por entero protegida de una devaluación, ya sea porque los usuarios finales reciban sus ingresos en divisas, o porque se han protegido de las fluctuaciones cambiarias mediante la compra de instrumentos financieros derivados. ${ }^{34}$

Finalmente, un tercer tema de cuidado para el sistema financiero neozelandés es el relativo a la supervisión prudencial; nos concentraremos en este párrafo a su manejo en un contexto en el cual el sistema bancario está muy concentrado y los cuatro bancos de importancia sistémica son originarios de otra nación: Australia. Esta interdependencia plantea riesgos específicos para Nueva Zelanda, que ha llevado a las autoridades a introducir cambios legales y a buscar un diálogo con las autoridades supervisoras australianas. Así, entre los cambios regulatorios de gran importancia figura la obligación para los bancos de importancia sistémica de constituirse en empresa incorporada en el país, con el propósito de facilitar el acceso más rápido de las autoridades a los activos y pasivos de una institución en problemas, de asegurar un mayor nivel de gobernabilidad local del banco y de permitir una mayor difusión de su información financiera. Otra medida concierne a los límites puestos al traslado hacia el banco matriz de funciones clave que impedirían a la dirección del banco neozelandés tomar o llevar a cabo decisiones que permitirían la supervivencia independiente de éste en caso de que el banco matriz entrara en problemas graves. Esta medida responde al desplazamiento en los últimos años de sistemas de información y de puestos clave de dirección, que han sido reagrupados en las matrices para disminuir costos, y al temor de ver un banco neozelandés vaciado de sus activos para salvar al banco matriz, o para asegurar el pago de sus depósitos a los clientes australianos. En efecto, a diferencia de Nueva Zelanda, Australia ha adoptado un sistema de seguro de depósito, el que contiene una cláusula de acceso prioritario de los depositantes australianos a los activos ubicados en Australia, y se teme que esta característica pueda tener consecuencias dañinas para los depositantes neozelandeses, debido a la facilidad con la cual los activos del banco neozelandés pudieran ser trasladados a Australia. ${ }^{35}$ En suma, la integración de hecho de los sistemas bancarios de ambos países requiere cierto grado de cooperación de las autoridades financieras, así como un acercamiento en sus "estilos" de reglamentación prudencial y de supervisión. Así, Nueva Zelanda se ve empujada a reformar ciertos aspectos de su sistema de reglamentación y supervisión prudencial, más liberal en comparación con el australiano, más activo e intervensionista, para evitar que estas características tornen la integración en algo perjudicial para los depositantes neozelandeses en caso de producirse una crisis financiera. 


\section{Conclusión}

El ejemplo de Nueva Zelanda muestra que reformas financieras radicales pueden llevar a un desarrollo significativo y rápido del sistema financiero, sin por ello acarrear una crisis sistémica o problemas de gran envergadura en instituciones de importancia sistémica. En el contexto de una economía pequeña, los grandes bancos universales son los que han resultado ganadores de las reformas y ocupan hoy la escena financiera del país. Las instituciones financieras no bancarias, cuya importancia retrocedió con las reformas, están hoy desarrollándose también de manera muy dinámica.

Sin embargo, el predominio de los bancos y el carácter concentrado del sistema han hecho surgir preocupaciones de competencia insuficiente y de costos elevados para los clientes de menudeo, llevando así a la reintroducción de un banco de propiedad pública con la creación del Kiwibank. El carácter extranjero de los bancos de importancia sistémica lleva también hacia otros debates, relacionados con el papel de estas instituciones en la balanza de pagos, en el financiamiento internacional del país, y con la interdependencia que producen con el sistema financiero y el marco de reglamentación y supervisión prudencial de Australia. La actual posición financiera de Nueva Zelanda parece riesgosa a pesar de su excelente desempeño económico, en la medida en que combina un bajo nivel de ahorro y un alto endeudamiento de las familias, un profundo déficit en cuenta corriente y un financiamiento cada vez más dependiente de flujos bancarios de corto plazo, combinación que resultó una bomba de tiempo en numerosas economías, por cierto de menor nivel de desarrollo. Está por verse si la condición de país desarrollado de Nueva Zelanda, la solidez de sus instituciones y su marco de supervisión justifican el optimismo oficial ante estos riesgos. my

\section{Notas}

1 Butcher, David, y asociados (1997) Economic Reforms in New-Zealand, marzo. Disponible en: http://wwwbda.org.nz/PDFs/New por ciento20Zealandand por ciento20Reform por ciento201997.pdf.

2 Scollay, Robert, y Susan St. John (1996) Macroeconomics and the Contemporary New Zealand Economy, Longman Ed.

3 Estos intentos fallidos se dieron en la década de los sesenta, a inicios de los setenta y en 1976 (Butcher y asociados, op. cit., p. 5).

4 Buckle, Robert A. (1987) "Sequencing and the Role of the Foreign Exchange Market", en A. Bollard y R. A. Buckle (eds.), Economic Liberalization in New Zealand, Allen and Unwin, citado en Grimes, Arthur (1996) "Monetary Policy", en Brian Silverstone, Allan Bollard y Ralph Latimore (ed.), A Study of Economic Reform: The case of New Zealand, Elsevier Science B. V., pp. 248-278.

5 Brash, Donald T. (1996) New Zealand remarkable reforms. An address by Donald T. Brash, Governor of the Reserve Bank of New Zealand to the Fifth Annual Hayek Memorial Lecture, 4 de junio. Londres: Institute of Economic Affairs, pp. 8 y 9. http://www.rbnz.govt.nz/ speeches/0031201.html

6 Grimes, op. cit.

7 Butcher y asociados, op. cit., p. 8.

8 La privatización del Banco de Desarrollo (DFC) (1988), de la aseguradora State Insurance Office (1990), de la compañía Landcorp Financial Instruments (1990) y de una cartera de hipotecas de la Housing Corporation (1991-1993) completan las ventas de participaciones del gobierno neozelandés en instituciones financieras. Véase Scollay y St John, op. cit., cuadro 9.3, p. 323.

9 Steel, Jeremy, y David Craig (2002) "New Zealand", International Financial Law Review - Supplement Banking Yearbook 2002, pp. 4957.

10 La problemática del seguro de depósitos es muy debatida debido a los efectos colaterales indeseados que presenta su introducción (azar moral); sin embargo, pocos países se "atreven" a no tenerlo del todo, pues su ausencia puede implicar pánicos y corridas bancarias en caso 
de dudas acerca de la salud financiera de una o de más instituciones. Sin embargo, los supervisores neozelandeses están muy apegados a esta especificidad de su sistema prudencial y precisan las razones que tienen para ello en Reserve Bank of New Zealand, Bank deposit insurance and why we don't have it in New Zealand, disponible en http://www.rbnz.govt. nz/finstab/banking/regulation/0154814.html.

11 Scollay y St John, op. cit., pp. 290-291.

12 мі (2004) "New Zealand: Financial System Stability Assessment", Country Report, núm. 04/126, mayo, Washington D. C, p. 23.

13 Reserve Bank of New Zealand (2004) Financial Stability Report, octubre, p. 13, disponible en: http://www.rbnz.govt.nz/finstab/fsr_oct2004. pdf.

14 Ibid., cuadro A2, p. 40.

15 Los datos del Banco de Reserva no incluyen financieras o uniones de crédito más pequeñas, que esta institución no supervisa.

16 Esta caracterización radica en que la quiebra de una de estas instituciones bastaría para poner en grave riesgo al sistema financiero en su conjunto.

17 Véase el análisis de este tema en Smith, Robert, y David Tripe (2001) Competition and Contestability in New Zealand's Banking System, ponencia presentada en la XIVth Australasian Finance and Banking Conference, Sydney, diciembre. Consultado en http://centre-banking-studie. massey.ac.nz/research_outputs/competitionandcontestability.pdf. Los autores muestran que en el periodo comprendido entre 1996 y 1999 el sistema bancario neozelandés funcionó bajo condiciones de competencia monopolística.

18 Steel y Craig, op. cit.

19 Recordamos que PostBank había sido separada de las demás actividades de la Oficina de Correos y privatizada en 1989. Sobre los resultados iniciales del banco, véase Unlimited Magazine Kiwibank-success or something less, disponible en http://www.sharechat.co.nz/features/unlimited/article.php/a4543e6e, y The success of Kiwibank, http://www.scoop.co.nz/stories/ PA0207/S00495.htm.
20 Véase Approval given for Kiwibank move to business banking, http://www.marketing.org. nz/cms/News/1175 y Kiwibank Declares SixMonth Profit, disponible en http://www.workplacesolutions.co.nz/50070.html.

21 Tripe, David (2004) "The New Zealand Banking System and the Balance of Payments", Paper for $8^{\text {th }}$ New Zealand Finance Colloquium, Hamilton, enero. Disponible en: http://centrebanking-studies.massey.ac.nz/research_output/ BalanceofPayments.pdf.

22 Reserve Bank of New Zealand (2004) Financial Stability Report, p. 13, octubre. Disponible en http://www.rbnz.govt.nz/finstab/fsr_oct2004. pdf

23 El alza de los precios del sector inmobiliario se atribuye, por lo menos en parte, a los flujos migratorios positivos que ha conocido Nueva Zelanda en los últimos años, los cuales han elevado la demanda de viviendas.

24 FMI (2005) "New Zealand: 2005 Article IV Consultation-Staff Report", Country Report, núm. 05/152, anexo 1, mayo, Washington D. C., p. 35.

25 FMI (2005) “New Zealand: Selected Issues", Country Report, núm. 05/153, mayo, Washington D. C., p. 41.

26 FMI, op. cit., p. 43.

27 Lustig, Hanno, y Stijn Van Nieuwerburgh (2004) "Housing collateral and the Sensitivity of House Prices to Monetary Policy: Theory and Evidence", National Bureau of Economic Research Working Paper 10505, citado en FMI, op. cit., p. 41.

28 Reserve Bank of New Zealand, op. cit.

29 FMI, op. cit., p. 5.

30 FMI, op. cit., anexo 1, pp. 31 y 32.

31 Tripe, op. cit., p. 10.

32 Ídem.

33 En el caso argentino, donde se destacaban similares características, la propiedad extranjera del sistema bancario no ha brindado las garantías esperadas cuando estalló la crisis.

34 FMI (2005) "New Zealand: 2005 Article IV Consultation-Staff Report”, op. cit.

35 FMI (2004) "New Zealand: Financial System Stability Assessment”, op. cit., p. 27. 